\title{
Preparation of Micron-sized Monodisperse Poly (Styrene-co-methyl Methacrylate) Microspheres by Dispersion Copolymerization
}

\author{
Huichun $\mathrm{Chu}^{\mathrm{a}}$, Qinmin Pan ${ }^{\mathrm{b}}$ \\ Green Polymer and Catalysis Technology Laboratory, \\ College of Chemistry, Chemical Engineering and
}

\begin{abstract}
Micron-sized monodisperse copolymer microspheres were prepared by dispersion copolymerization of styrene (St) and methyl methacrylate (MMA) in ethanol/water medium using 2,2'-azobis (isobutyronitrile) (AIBN) and poly (vinyl pyrrolidone) (PVP) as initiator and steric stabilizer, respectively. The effect of several important polymerization parameters such as polarity of the medium, concentrations of stabilizer, initiator, and monomers on the particle size and size distribution of the resulting particles were investigated. It was found that a higher MMA content in the reaction recipe requires a higher polarity of the medium in order to produce uniform poly (St-co-MMA) particles. A minimum value of the PVP concentration and a maximum value of the AIBN concentration should not be exceeded for the preparation of monodisperse copolymer microspheres. The particle size decreases with an increase of the PVP concentration when the PVP concentration is above the minimum value or an increase of the AIBN concentration when the AIBN concentration is below the maximum value. A lower monomer concentration is favorable to generate smaller microspheres, while larger microspheres can be obtained at a higher concentration of monomers.
\end{abstract}

Keywords-monodisperse, micron-sized, copolymer
microspheres, dispersion (styrene-co-methyl methacrylate).

\section{INTRODUCTION}

Functional monodisperse polymer microspheres in the micron size range have a variety of scientific and technological applications, such as calibration standards for instruments, column packing materials for chromatographic separation, spacers for liquid crystal display panel, toners for printing, and bioseparators, immunoassay and indicators for biomedical and biochemical analysis[1-5]. Such type of microspheres can be prepared by the successive seeding method developed by Vanderhoff et al.[6], the two-stage swelling method proposed by Ugelstad et al.[7], or the dynamic monomer swelling method developed by Okubo et al.[8]. However, these techniques are complicated, time-consuming and also difficult to implement on a large scale.

Dispersion polymerization is an attractive and promising alternative to other polymerization techniques that affords micrometer-sized monodisperse microspheres in a single batch process. To produce functional microspheres, one common strategy that is dispersion copolymerization has been extensively adopted[9-15]. However, some undesired results such as polydisperse

\author{
Materials Science, Soochow University, Suzhou 215123, \\ Jiang Su, P.R. China \\ achuhuichun@126.com, bqpan@suda.edu.cn \\ (Corresponding Author)
}

particle sizes and coagulum were often observed when a small amount of cross-linking agent, dye-comonomer, or even hydrophilic monomers were present at the start of polymerization[16-21]. Song et al. [22-24] proposed a strategy of delaying the addition of these problematic species after nucleation stage of dispersion polymerization, which was referred to as two-stage dispersion polymerization, to overcome relevant problems if the problematic reagents are present at the beginning of the reaction and their results indicated that dye-labeled beads, cross-linked beads, or functionalized beads with an exceptionally narrow size distribution and with control over bead diameter were synthesized in this way.

To further examine the problems that have been indicated above, we carried out batch dispersion copolymerization of St and MMA in EtOH/ $\mathrm{H}_{2} \mathrm{O}$ medium using AIBN and PVP as initiator and steric stabilizer, respectively, aiming at synthesizing uniform poly(St-co-MMA) microspheres via a much simpler method. It was interestingly found that micron-sized monodisperse poly (St-co-MMA) particles with a higher MMA content in the initial monomers could be prepared by increasing the polarity of the medium which could be easily tuned by changing the volume ratio of water in the medium. Then, we further studied the influence of several important polymerization parameters such as concentrations of stabilizer, initiator, and monomers on the particle size and size distribution of the resulting particles.

\section{EXPERIMENTAL}

\section{A. Materials}

Styrene (St, AR) and methyl methacrylate (MMA, AR) were purchased from Sinopharm Chemical Reagent Co., Ltd. (China), purified by passing through a neutral alumina column and then stored in the refrigerator before use for no longer than two weeks. 2, 2'-azobis (isobutyronitrile) (AIBN) was purified by recrystallization in methanol before use. Poly (vinyl pyrrolidone) (PVP, $M_{\mathrm{w}}=58,000$ ) and ethanol (EtOH, AR) were obtained from Aladdin Chemistry Co., Ltd. and Chinasun Specialty Products Co., Ltd. (China), respectively. Deionized water $\left(\mathrm{H}_{2} \mathrm{O}\right)$ used all through the experiments was generated in our lab.

\section{B. Synthesis of monodisperse poly (St-co-MMA) microspheres by dispersion copolymerization}

Poly (St-co-MMA) microspheres were synthesized by dispersion copolymerization of St and MMA in EtOH/ $\mathrm{H}_{2} \mathrm{O}$ medium using PVP as dispersant and AIBN as initiator. 
Typically, all the ingredients including the monomers $\mathrm{St}$ and MMA, the initiator AIBN, the stabilizer PVP, and the medium EtOH $/ \mathrm{H}_{2} \mathrm{O}$ mixture were charged into $50 \mathrm{~mL}$ flask. The reaction system was deoxygenated by purging with nitrogen for at least $30 \mathrm{~min}$ after a homogeneous solution was formed under magnetic agitation. Then, the flask was capped, sealed, and immersed in a $70{ }^{\circ} \mathrm{C}$ thermostatic oil bath for $24 \mathrm{~h}$ with magnetic agitation.

The total monomer conversion was determined by gravimetrical analysis. Briefly, a given amount of dispersion was withdrawn from the final product, dried at $70{ }^{\circ} \mathrm{C}$ overnight, and the remained solids were weighed. The conversion was calculated using the following equation:

$$
\text { Con. } \%=\frac{\frac{\mathrm{m}_{1}}{\mathrm{~m}_{0}} \times\left(\mathrm{m}_{\mathrm{St}}+\mathrm{m}_{\mathrm{MMA}}+\mathrm{m}_{\left.\mathrm{AP}+\mathrm{m}_{\mathrm{M}}\right)-\mathrm{m}_{\mathrm{AP}}}\right.}{\mathrm{m}_{\mathrm{St}}+\mathrm{m}_{\mathrm{MMA}}} \times 100 \% .
$$

where $\mathrm{m}_{0}$ and $\mathrm{m}_{1}$ represent the masses of the withdrawn dispersion and the remained solids, respectively. The $\mathrm{m}_{\mathrm{St}}$, $\mathrm{m}_{\mathrm{MMA}}, \mathrm{m}_{\mathrm{AP}}$ and $\mathrm{m}_{\mathrm{M}}$ are, respectively, the masses of $\mathrm{St}$, MMA, medium and the total mass of AIBN and PVP prior to the polymerization.

To remove the oligomers, the unreacted monomers and the remaining initiator, the resulting microspheres were purified by repeated centrifugation and redispersion in EtOH process. If dried powder was needed, the cleaned microspheres were dried under vacuum at ambient temperature overnight

\section{Characterization}

Fourier transform infrared spectroscopy (FTIR) was used for composition analysis conducted on a Nicolet iS 10 FTIR spectrometer with power-pressed $\mathrm{KBr}$ pellets. Scanning electron microscopy (SEM) used for morphology observation and its images were obtained using a Hitachi S-4700 field emission electron microscope operating at 15 $\mathrm{kV}$. Samples for SEM were prepared by drying one drop of the dilute dispersion of the washed microspheres onto a small piece of glass plate and then sputtered with gold. The number average diameter and the coefficient of variation of the washed microspheres were calculated using the following two equations by counting at least 150 individual particles from the SEM images.

$$
D_{n}=\frac{\sum n_{i} d_{i}}{\sum n_{i}}
$$

$C_{v}, \%=\frac{\left(\frac{\sum\left(d_{i}-D_{n}\right)^{2}}{n-1}\right)^{0.5}}{D_{n}}$.

where $D_{n}$ and $C_{v}$ represent the number average diameter and the coefficient of variation, respectively. $n$ is the total number counted and $d_{i}$ the diameter of particle $i$.

\section{RESULTS AND DISCUSSION}

Dispersion polymerization is a type of heterogeneous polymerization process in which the monomer, the initiator and the stabilizer are all dissolved in the polymerization medium at the beginning, however the polymer chains when they reach their critical length will precipitate from the medium and be stabilized by absorbing sufficient grafted steric stabilizer after the start of the polymerization[25]. Polymerization can happen in the particle phase and the continuous phase simultaneously because of the partition of monomer and initiator in both phases[26]. It is obvious that the medium has a significant effect on the critical chain length of precipitated polymers, monomer partitioning behavior and locus of polymerization, thus affects the whole polymerization. So we studied the polarity of the medium first as it is a primary factor.

\section{A. Effect of water content in the medium}

Batch dispersion copolymerization of St and MMA was conducted with different mass ratios (St/MMA $=100 / 0 \sim 0 / 100, \mathrm{w} / \mathrm{w})$ in the medium with different polarities $\left(\mathrm{EtOH} / \mathrm{H}_{2} \mathrm{O}=100 / 0 \sim 80 / 20, \mathrm{v} / \mathrm{v}\right)$. Typical recipes are presented in Table 1 . The composition of poly (St-co-MMA) microspheres was confirmed by FTIR spectroscopy measurements (see Fig. 2). In curve 1, peaks at $1601 \mathrm{~cm}^{-1}, 1494 \mathrm{~cm}^{-1}$ and $1453 \mathrm{~cm}^{-1}$ correspond to characteristic aromatic $\mathrm{C}=\mathrm{C}$ stretching vibrations and bands at $754 \mathrm{~cm}^{-1}$ and $699 \mathrm{~cm}^{-1}$ are assigned to mono-substituted aromatic ring. Compared with the IR spectrum of PS microspheres in curve 1, the presence of typical peak of $\mathrm{C}=\mathrm{O}$ groups $\left(1729 \mathrm{~cm}^{-1}\right)$ and broad bands in the region $1300-1000 \mathrm{~cm}^{-1}$ assigned to $\mathrm{C}-\mathrm{O}$ stretching vibrations in curve 2,3 and 4 indicated the copolymerization of St and MMA.

TABLE 1 TYPICAL RECIPES FOR BATCH DISPERSION COPOLYMERIZATION OF ST AND MMA IN ETOH $/ \mathrm{H}_{2} \mathrm{O}$ MEDIUM ${ }^{\mathrm{A}}$

\begin{tabular}{cc}
\hline Ingredients & Amounts $(\mathrm{g})$ \\
\hline $\mathrm{St}$ & $\mathrm{x}^{\mathrm{b}}$ \\
MMA & $\mathrm{y}^{\mathrm{b}}$ \\
$\mathrm{AIBN}$ & 0.040 \\
$\mathrm{PVP}$ & 0.400 \\
EtOH $+\mathrm{H}_{2} \mathrm{O}^{\mathrm{b}}$ & 24.0 \\
\hline
\end{tabular}

a Polymerization conditions: $30 \mathrm{~min} \mathrm{~N} 2$, capped and sealed flask, $70{ }^{\circ} \mathrm{C}$ oil bath, magnetic agitation, $24 \mathrm{~h}$. $\mathrm{b} x+\mathrm{y}=4.00$

b For EtOH/H2O = 100/0 (v/v), x/y = 100/0, 95/5, 90/10, 80/20, 75/25, $50 / 50(\mathrm{w} / \mathrm{w})$

b For $\mathrm{EtOH} / \mathrm{H} 2 \mathrm{O}=90 / 10,80 / 20(\mathrm{v} / \mathrm{v}), \mathrm{x} / \mathrm{y}=100 / 0,75 / 25,50 / 50,25 / 75$, $0 / 100(\mathrm{w} / \mathrm{w})$

As shown in Fig. 1, the total conversion of monomers decreases with the increase of MMA content in the initial monomers when the same medium was applied. However, more $\mathrm{H}_{2} \mathrm{O}$ content in the medium led to significantly higher total conversion of monomers when monomers of the same composition were polymerized. This suggests that the reaction system is quite sensitive to the $\mathrm{H}_{2} \mathrm{O}$ content in the medium. It is because the shift of main polymerization locus from the continuous phase to the particle phase, which accelerates the polymerization speed. 


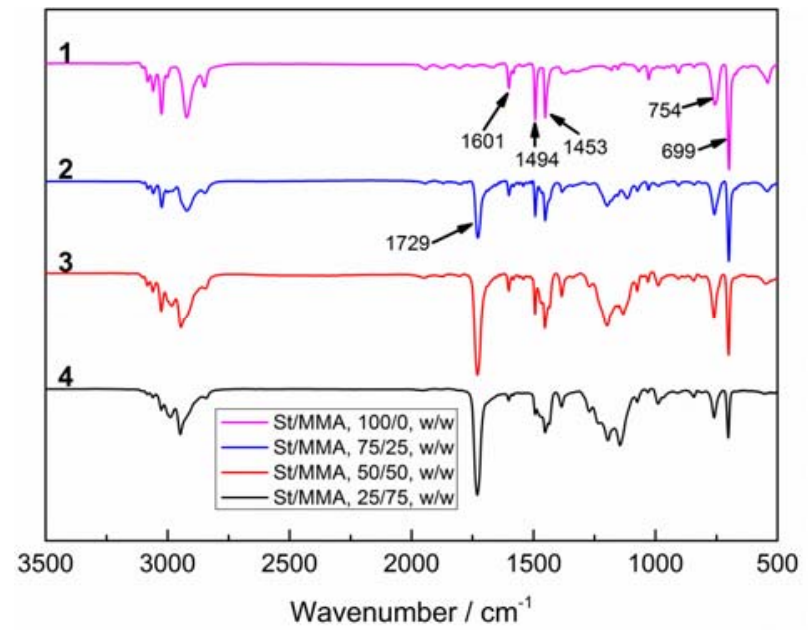

Figure 1. FTIR spectra of poly (St-co-MMA) microspheres at different mass ratios of St and MMA.

Reactions conditions: $24.0 \mathrm{~g}$ of $80 / 20 \mathrm{v} / \mathrm{v}$ EtOH/H2O medium, $4.00 \mathrm{~g}$ monomers, $0.40 \mathrm{~g}$ PVP, $0.040 \mathrm{~g}$ AIBN, N2, magnetic agitation, $70^{\circ} \mathrm{C}, 24$ $\mathrm{h}$.

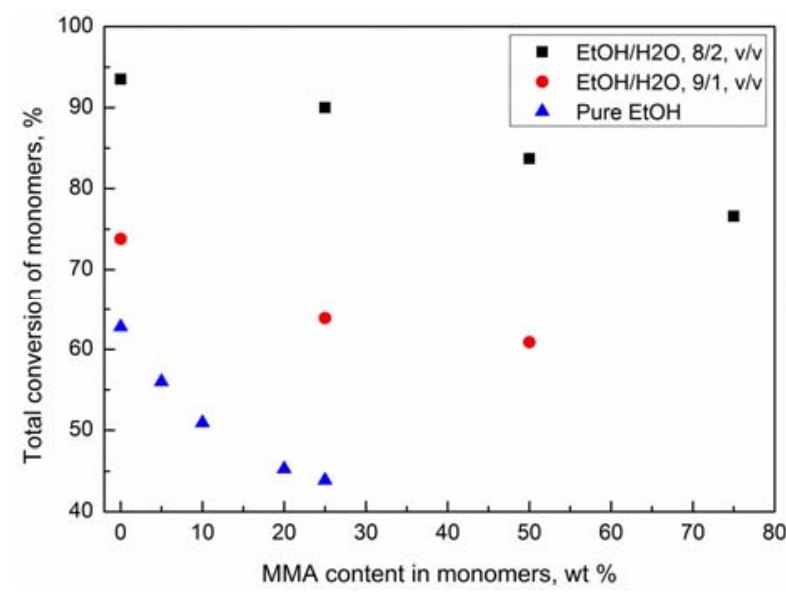

Figure 2. Total conversion of monomers versus MMA content in the initial monomers in various $\mathrm{EtOH} / \mathrm{H} 2 \mathrm{O}$ medium.

Conditions: 24.0 g medium, 4.00 g monomers, 0.40 g PVP, 0.040 g AIBN, $\mathrm{N} 2$, magnetic agitation, $70{ }^{\circ} \mathrm{C}, 24 \mathrm{~h}$.

To check the uniformity of copolymer microspheres, SEM tests were carried out. Different from the result reported in the literature[16], in the pure ethanol solvent system, monodisperse poly(St-co-MMA) microspheres with MMA content up to $10 \mathrm{wt} \%$ (based on the total mass of initial monomers) as shown in Fig. 3 could be obtained. With a high MMA content, polydisperse particles appeared. For polymerization in the more polar medium $\left(\mathrm{EtOH} / \mathrm{H}_{2} \mathrm{O}\right.$, $90 / 10, \mathrm{v} / \mathrm{v})$, particles containing up to $25 \mathrm{wt} \% \mathrm{MMA}$ content (see Fig. 4) could be prepared without a significant change in the narrow particle size distribution. Further increasing the amount of water in the medium $\left(\mathrm{EtOH} / \mathrm{H}_{2} \mathrm{O}\right.$, $80 / 20, \mathrm{v} / \mathrm{v})$, Figure 5 shows that microspheres synthesized at high MMA content ( $50 \mathrm{wt} \%$ ) are still monodisperse. However, popcorn-like particles were formed when dispersion copolymerization of monomers $(\mathrm{St} / \mathrm{MMA}=25 / 75, \mathrm{w} / \mathrm{w})$ was conducted in $80 / 20 \mathrm{v} / \mathrm{v}$ $\mathrm{EtOH} / \mathrm{H}_{2} \mathrm{O}$ medium. We believe that as MMA was more soluble in the medium than $\mathrm{St}$, the critical chain length at which the polymer started to precipitate increased, and the efficiency of grafted stabilizer decreased. Thus, the nucleation stage was prolonged, which allows the existence of both small and large particles. With the process of polymerization, the remaining stabilizer was insufficient to maintain the colloidal stability of the growing particles and particles coagulated with each other to reduce surface potential. From the results above, it can be concluded that increasing the polarity of the medium is suitable for the production of monodisperse poly (St-co-MMA) particles with a high MMA content in the initial monomers. This phenomenon can be explained as follows: with an increase in $\mathrm{H}_{2} \mathrm{O} / \mathrm{EtOH}$ volume ratio, the solubility of monomers and related polymer decreased, so the polymerization system became more heterogeneous, which would decrease the critical chain length and shorten the growing period of chains in continuous phase; as a result, monodisperse particles with a high MMA content in the initial monomers were produced; however, if the MMA/St ratio exceeds a critical value, solubility of MMA in the solution would induce much longer growing period of chains in continuous phase and the more soluble grafted steric stabilizer and thus cause coalescence of unstable particles, which resulted in broader size distribution of particles and even popcorn-like particles.

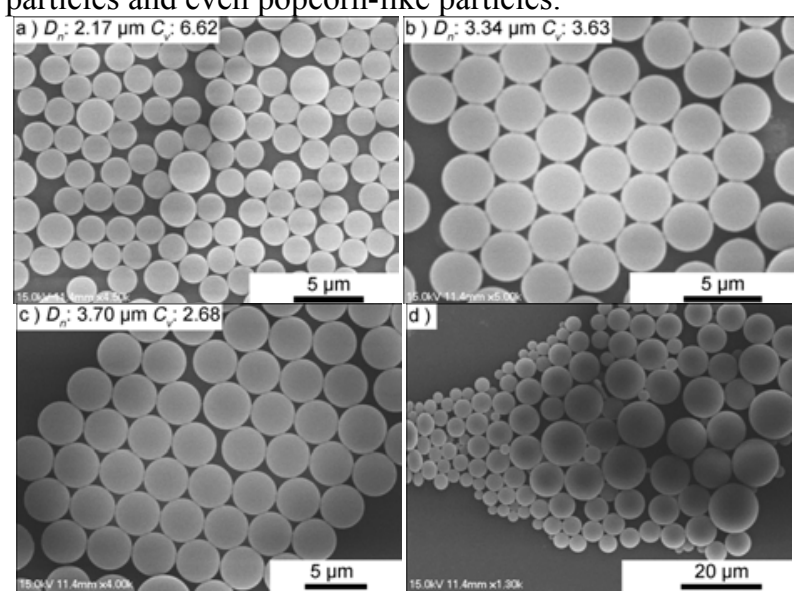

Figure 3. SEM images of poly (St-co-MMA) microspheres at various mass ratios of initial monomers:

St/MMA (w/w) = a) 100/0; b) 95/5; c) 90/10; d) 80/20. Other polymerization conditions: $24.0 \mathrm{~g} 100 / 0 \mathrm{v} / \mathrm{v}$ EtOH/H2O medium medium, $4.00 \mathrm{~g}$ monomers, $0.040 \mathrm{~g}$ AIBN, $0.40 \mathrm{~g}$ PVP, N2, magnetic agitation, $70^{\circ} \mathrm{C}, 24 \mathrm{~h}$. 


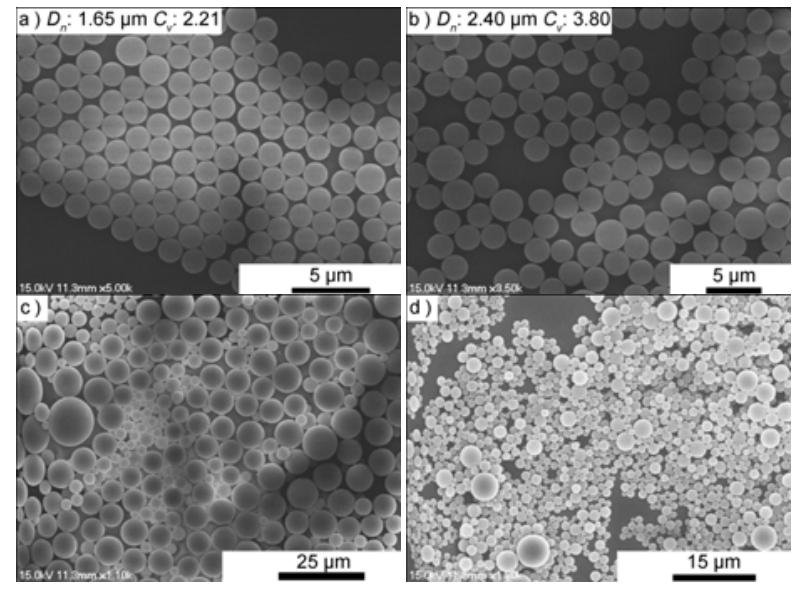

Figure 4. SEM images of poly (St-co-MMA) microspheres at various initial monomers:

St/MMA (w/w) = a) $100 / 0$; b) $75 / 25$; c) $50 / 50$; d) 25/75. Other polymerization conditions: $24.0 \mathrm{~g} 90 / 10 \mathrm{v} / \mathrm{v} \mathrm{EtOH} / \mathrm{H} 2 \mathrm{O}$ medium medium, $4.00 \mathrm{~g}$ monomers, $0.040 \mathrm{~g}$ AIBN, $0.40 \mathrm{~g}$ PVP, N2, magnetic agitation, $70{ }^{\circ} \mathrm{C}, 24 \mathrm{~h}$.

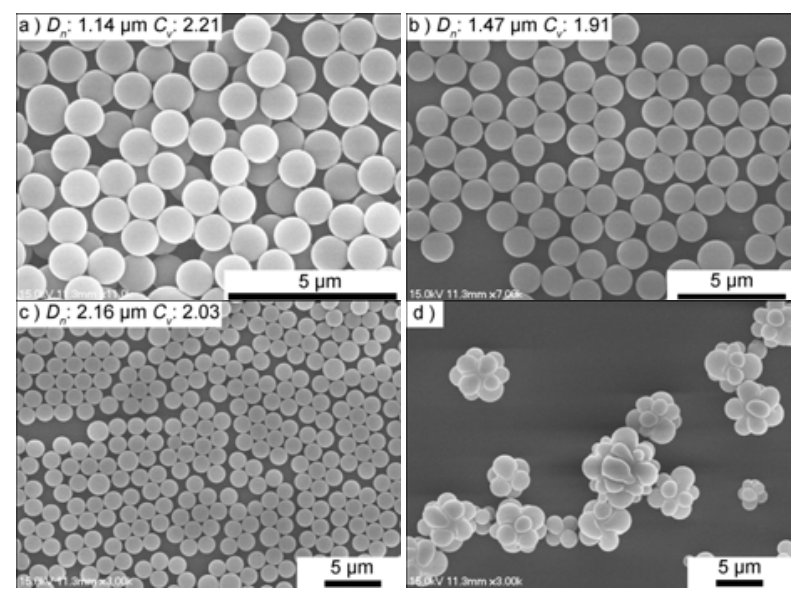

Figure 5. SEM images of poly (St-co-MMA) microspheres at various initial monomers:

St/MMA (w/w) = a) 100/0; b) 75/25; c) 50/50; d) 25/75. Other polymerization conditions: $24.0 \mathrm{~g} \mathrm{80/20} \mathrm{v/v} \mathrm{EtOH/H2O} \mathrm{medium,} 4.00 \mathrm{~g}$ monomers, $0.040 \mathrm{~g}$ AIBN, $0.40 \mathrm{~g}$ PVP, N2, magnetic agitation, $70{ }^{\circ} \mathrm{C}, 24$ h.

The effects of some other important parameters such as concentrations of stabilizer, initiator, and monomers on the particle size and size distribution of the resulting particles at the fixed initial monomer ratio $(\mathrm{St} / \mathrm{MMA}=50 / 50, \mathrm{w} / \mathrm{w})$ in $80 / 20 \mathrm{v} / \mathrm{v} \mathrm{EtOH} / \mathrm{H}_{2} \mathrm{O}$ were further investigated.

\section{B. Effect of PVP concentration}

The influence of PVP concentration on particle size and size distribution is given in Fig. 6. When PVP concentration was low (see Fig. 6 a) and b)), the microspheres were polydisperse because of insufficient stability of particles. Then, with an increase of PVP concentration, microspheres with narrow size distribution could be obtained and the particle size became smaller. The reason is that with the increase of the PVP concentration, the viscosity of the continuous phase, the rate of physical adsorption of PVP and anchoring adsorption of grafted PVP were increased[27], which means that more mature nuclei can be stabilized and thus the particle size is reduced. So, for the preparation of monodisperse poly (St-co-MMA) microspheres, there exists a minimum value of PVP concentration.

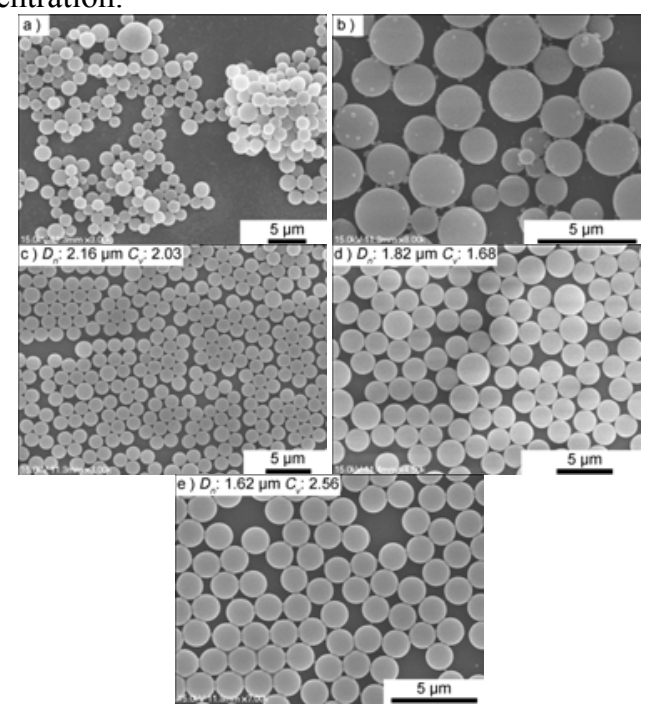

Figure 6. SEM images of poly (St-co-MMA) microspheres using different amount of PVP:

a) $0.10 \mathrm{~g}$; b) $0.20 \mathrm{~g}$; c) $0.40 \mathrm{~g}$; d) $0.60 \mathrm{~g}$; e) $0.80 \mathrm{~g}$. Other polymerization conditions: $24.0 \mathrm{~g} 80 / 20 \mathrm{v} / \mathrm{v} \mathrm{EtOH} / \mathrm{H} 2 \mathrm{O}$ medium, $4.00 \mathrm{~g} \mathrm{50/50 \textrm {w } / \mathrm { w }}$ $\mathrm{St} / \mathrm{MMA}$ monomers, $0.040 \mathrm{~g}$ AIBN, N2, magnetic agitation, $70^{\circ} \mathrm{C}, 24 \mathrm{~h}$.

\section{Effect of AIBN concentration}

The influence of AIBN concentration on particle size and size distribution is shown in Fig. 7. With an increase in AIBN concentration, the particle size of microspheres with narrow size distribution became larger due to a longer growing period of chains led by chain termination. Further increasing the concentration of AIBN, microspheres with board size distribution would be obtained. That is because fewer monomers were grafted onto PVP due to the enhanced radical termination at a higher AIBN concentration and thus the rate of anchoring grafted PVP is reduced, which would increase the coagulation rate of unstable nuclei to form larger permanent particle nuclei. Therefore, there exists a maximum dosage of AIBN for the preparation of monodisperse poly (St-co-MMA) microspheres. 


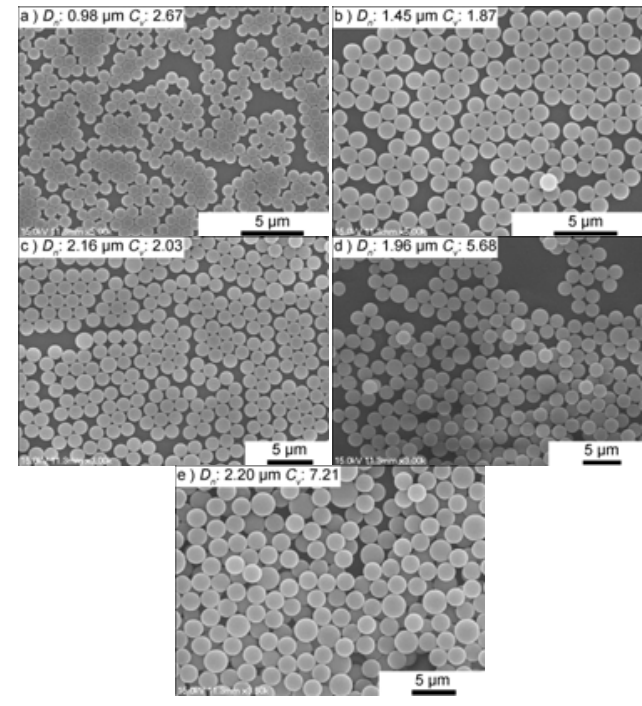

Figure 7. SEM images of poly (St-co-MMA) microspheres using different amount of AIBN:

a) $0.010 \mathrm{~g}$; b) $0.020 \mathrm{~g}$; c) $0.040 \mathrm{~g}$; d) $0.060 \mathrm{~g}$; e) $0.080 \mathrm{~g}$. Other polymerization conditions: $24.0 \mathrm{~g} 80 / 20 \mathrm{v} / \mathrm{v}$ EtOH/H2O medium, $4.00 \mathrm{~g}$ $50 / 50 \mathrm{w} / \mathrm{w}$ monomers, $0.40 \mathrm{~g}$ PVP, N2, magnetic agitation, $70^{\circ} \mathrm{C}, 24 \mathrm{~h}$.

\section{Effect of monomers concentration}

The influence of monomers concentration on particle size and size distribution is shown in Fig. 8. All the microspheres prepared under these conducted experiments were in uniform size. It is reasonable to conclude that 0.40 g PVP was sufficient to stabilize the nuclei generated even using $7.00 \mathrm{~g}$ monomers. The number average particle size decreased from $1.94 \mu \mathrm{m}$ to the minimum value $1.41 \mu \mathrm{m}$ and then increased to $2.65 \mu \mathrm{m}$. When the monomers concentration was low (see Fig. 8 a) and b)), the number of nuclei was significantly increased due to faster chain propagation in the continuous phase, so the particle size was reduced even when more monomers were applied. When the monomers concentration was high (see Fig. $8 \mathrm{c}$ ), d), e)), the particle size increased because more monomers that could be consumed during the growth stage of particles.

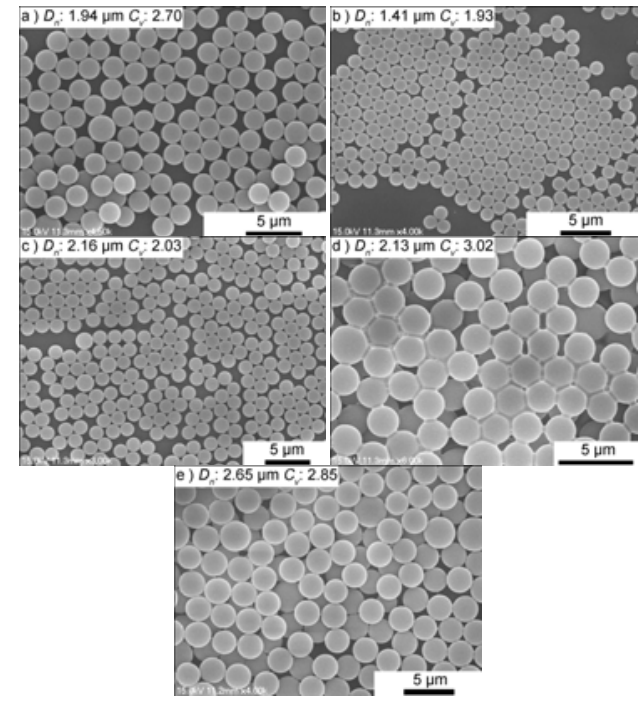

Figure 8. SEM images of poly (St-co-MMA) microspheres using different amount of $50 / 50 \mathrm{w} / \mathrm{w}$ St/MMA monomers:

a) $1.40 \mathrm{~g}$; b) $2.80 \mathrm{~g}$; c) $4.00 \mathrm{~g}$; d) $4.80 \mathrm{~g}$; e) $7.00 \mathrm{~g}$. Other conditions: the amount of medium was varied to make the total mass of $80 / 20 \mathrm{v} / \mathrm{v}$ $\mathrm{EtOH} / \mathrm{H} 2 \mathrm{O}$ medium and 50/50 w/w St/MMA monomers fixed at $28.0 \mathrm{~g}$, $0.40 \mathrm{~g}$ PVP

$0.040 \mathrm{~g}$ AIBN, $\mathrm{N}_{2}, 70^{\circ} \mathrm{C}$, magnetic agitation, $24 \mathrm{~h}$

\section{CONCLUSIONS}

Micron-sized monodisperse poly (St-co-MMA) microspheres were prepared by dispersion copolymerization of St and MMA in EtOH $/ \mathrm{H}_{2} \mathrm{O}$ medium using AIBN and PVP as initiator and steric stabilizer, respectively. The reaction medium plays a key role in the dispersion copolymerization. The production of monodisperse poly (St-co-MMA) particles with higher MMA content in the initial monomers can be achieved by increasing the polarity of the medium. There exist a minimum value of PVP concentration and a maximum value of AIBN concentration for the preparation of monodisperse copolymer microspheres. The particle size decreases with the increase of PVP concentration above the minimum value or the decrease of AIBN concentration below the maximum value. Low concentration of monomers is favorable to produce small diameter microspheres, while large diameter microspheres can be obtained at a high concentration of monomers. In a word, micron-sized monodisperse poly (St-co-MMA) microspheres can be successfully prepared by dispersion copolymerization of $\mathrm{St}$ and MMA under favorable conditions.

\section{ACKNOWLEDGEMENT}

Financial support from the National Nature Science Foundation of China (No. 21176163), Suzhou Industrial Park, Shandong Yuhuang Chemical Co. Ltd., the Priority Academic Program Development of Jiangsu Higher Education Institutions, and the Program of Innovative Research Team of Soochow University are gratefully acknowledged. 


\section{REFERENCES}

[1] A.I. Abdelrahman, O. Ornatsky, D. Bandura, V. Baranov, R. Kinach, S. Dai, S.C. Thickett, S. Tanner and M.A. Winnik: J. Anal. Atom. Spectrom. Vol. 25 (2010), p. 260

[2] B.L. Gong, J.X. Zhu, L. Li, K.J. Qiang and L. Ren: Talanta Vol. 68 (2006), p. 666

[3] J. Ugelstad, A. Berge, T. Ellingsen, R. Schmid, T.N. Nilsen, P.C. Mork, P. Stenstad, E. Hornes and O. Olsvik: Prog. Polym. Sci. Vol. 17 (1992), p. 87

[4] J. Ugelstad, P.C. Mork, R. Schmid, T. Ellingsen and A. Berge: Polym. Int. Vol. 30 (1993), p. 157

[5] H. Kawaguchi: Prog. Polym. Sci. Vol. 25 (2000), p. 1171

[6] J.W. Vanderhoff, M.S. Elaasser, F.J. Micale, E.D. Sudol, C.M. Tseng, A. Silwanowicz, D.M. Kornfeld and F.A. Vicente: J. Disper. Sci. Technol. Vol. 5 (1984), p. 231

[7] J. Ugelstad and P.C. Mork: Adv. Colloid. Interface. Sci. Vol. 13 (1980), p. 101

[8] M. Okubo and M. Shiozaki: Polym. Int. Vol. 30 (1993), p. 469

[9] M. Riza, I. Capek, A. Kishida and M. Akashi: Angew. Makromol. Chem. Vol. 206 (1993), p. 69

[10] D. Horak, F. Svec and J.M.J. Frechet: J. Polym. Sci. Pol. Chem. Vol. 33 (1995), p. 2329

[11] S. Kawaguchi, M.A. Winnik and K. Ito: Macromolecules Vol. 28 (1995), p. 1159

[12] K. Tomita and T. Ono: Colloid. Polym. Sci. Vol. 287 (2009), p. 109

[13] S. Krishnamoorthy, M. Haria, B.E. Fortier-McGill, M.A.J. Mazumder, E.I. Robinson, Y. Xia, N.A.D. Burke and H.D.H. Stoever: J. Polym. Sci. Pol. Chem. Vol. 49 (2011), p. 192
[14] R. Karnati and W.T. Ford: J. Polym. Sci. Pol. Chem. Vol. 46 (2008), p. 3813

[15] T.L.L. Closson, C. Feng, A. Halupa and M.A. Winnik: Macromolecules Vol. 46 (2013), p. 2523

[16] C.M. Tseng, Y.Y. Lu, M.S. Elaasser and J.W. Vanderhoff: J. Polym. Sci. Pol. Chem. Vol. 24 (1986), p. 2995

[17] B. Thomson, A. Rudin and G. Lajoie: J. Polym. Sci. Pol. Chem. Vol. 33 (1995), p. 345

[18] R.P.A. Dullens, E.M. Claesson and W.K. Kegel: Langmuir Vol. 20 (2004), p. 658

[19] Q.H. Liu, J. Liu, J.-C. Guo, X.-L. Yan, D.-H. Wang, L. Chen, F.-Y. Yan and L.-G. Chen: J. Mater. Chem. Vol. 19 (2009), p. 2018

[20] D. Horak, F. Svec and J.M.J. Frechet: J. Polym. Sci. Pol. Chem. Vol. 33 (1995), p. 2961

[21] J.S. Song, L. Chagal and M.A. Winnik: Macromolecules Vol. 39 (2006), p. 5729

[22] J.S. Song, F. Tronc and M.A. Winnik: J. Am. Chem. Soc. Vol. 126 (2004), p. 6562

[23] J.S. Song and M.A. Winnik: Macromolecules Vol. 38 (2005), p. 8300

[24] J.S. Song, F. Tronc and M.A. Winnik: Polymer Vol. 47 (2006), p. 817

[25] A.J. Paine, W. Luymes and J. McNulty: Macromolecules Vol. 23 (1990), p. 3104

[26] Y.Y. Lu, M.S. Elaasser and J.W. Vanderhoff: J. Polym. Sci. Pol. Phys. Vol. 26 (1988), p. 1187

[27] S. Shen, E.D. Sudol and M.S. Elaasser: J. Polym. Sci. Pol. Chem. $\begin{array}{lllll}\text { Vol. } & 32 & \text { (1994), } & \text { p. } & 1087\end{array}$ 